TE WHARE WĀNANGA O TE ÜPOKO O TE IKA A MĀUI

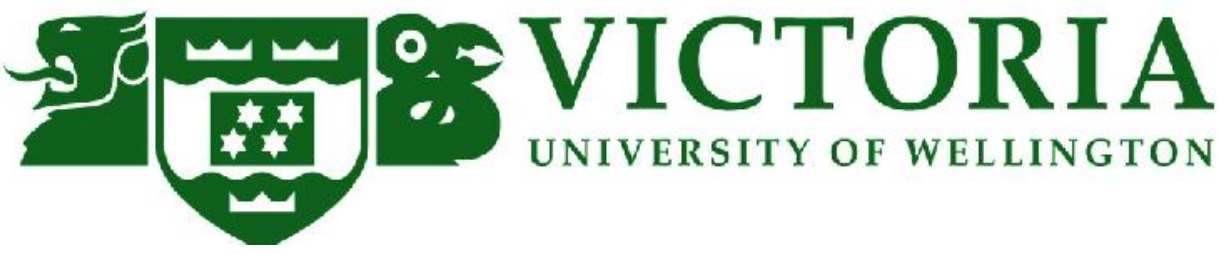

\title{
Exploring the challenges involved in migrating from an on-premises ECM solution to a SaaS based ECM
}

A Case Study presented to the

School of Information Management

Victoria University of Wellington

in partial fulfilment of the requirements for the degree of

Master of Information Management

by

M. F. Ali

October 2014 


\section{ABSTRACT}

\section{PURPOSE}

The objective of this research is to investigate the challenges that are acting as barriers to the adoption of a SaaS based ECM solution, mainly from an Information Technology viewpoint, in the wake of 'cloud first' policy that had been launched by the New Zealand government with the intent to maximize efficiencies across the public sector.

\section{METHODOLOGY}

Qualitative research was chosen for this research and outputs from the semi-structured interviews are compared with literature in order to highlight the commonalities and potentially highlighting any additional ones that exist with regards to the challenges that are associated with the adoption of a cloud based ECM service.

\section{PRACTICAL IMPLICATIONS}

This research will help organizations that have on-premises ECM solutions in making informed decisions through being aware of the challenges that act as barriers to adopting a SaaS based ECM solution through migrating from an on-premises ECM application.

\section{ORIGINALITY/ VALUE}

ECM in the context of a service based offering has been relatively little discussed in the literature. This research adds to the literature by examining ECM through the lens of cloud computing and investigates the challenges that are influencing its adoption.

\section{KEYWORDS}

enterprise content management, software as a service, challenges 


\section{ACKNOWLEDGEMENTS}

First and foremost, I wish to express my sincere gratitude and appreciation to my thesis advisor, Tony Hooper, for providing me with an opportunity to conduct this research under his auspices. I am greatly indebted to him for his guidance, encouragement, and constructive feedback throughout this research.

I would like to acknowledge our school's subject librarian, Philip Worthington, for sharing his knowledge on the references.

I appreciate the help and support of my colleagues and friends who were directly or indirectly involved in my research.

My deepest appreciation goes to my parents to whom I will be forever indebted for making me into who I am.

Last, but not by no means least, I would like to thank my beloved wife and children for their patience, support, and understanding, throughout the entire period of this study. 


\section{TABLE OF CONTENTS}

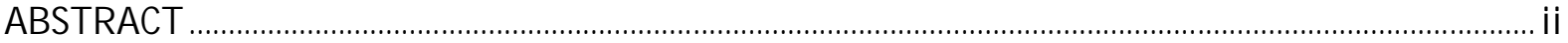

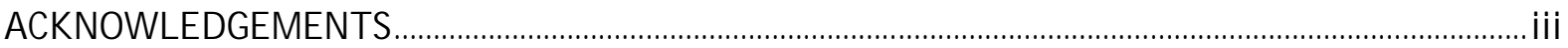

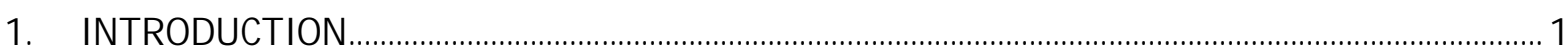

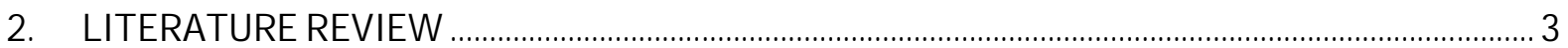

The background and overview of Software as a Service ................................................................................... 3

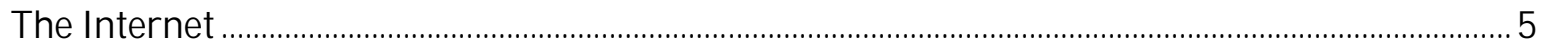

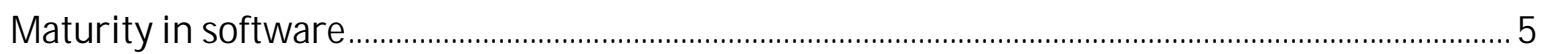

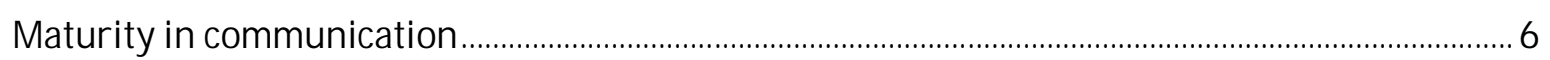

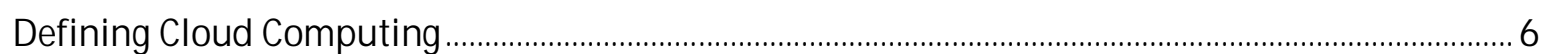

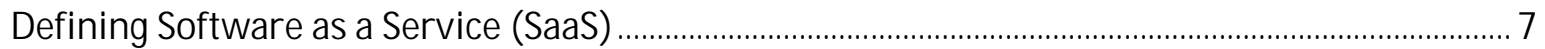

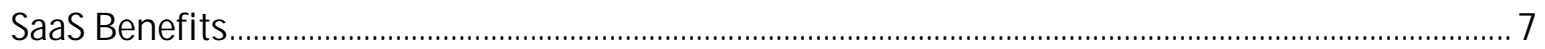

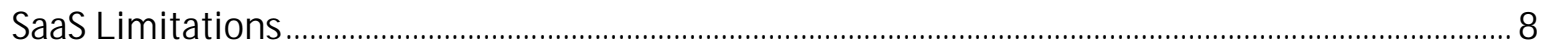

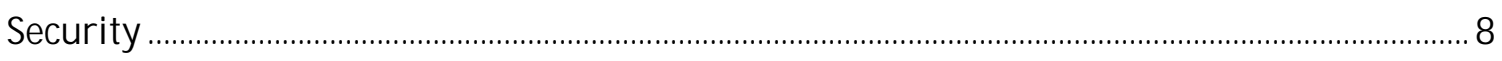

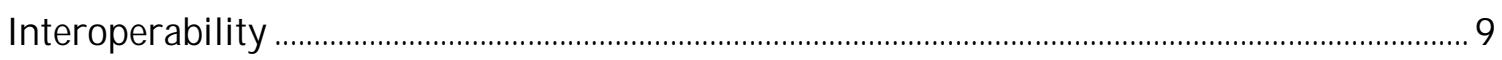

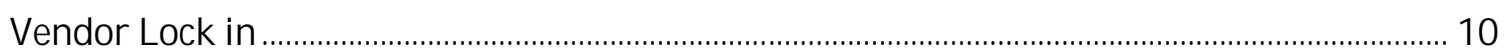

Reduced support for integration .......................................................................................................... 10

Data exchange ............................................................................................................................................. 11

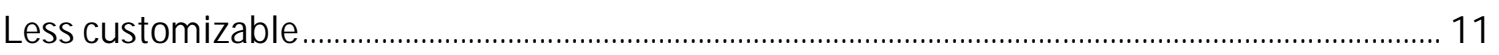

The background and overview of Enterprise Content Management (ECM) .................................... 11

Defining Enterprise Content Management................................................................................................... 12

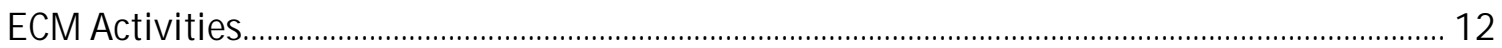

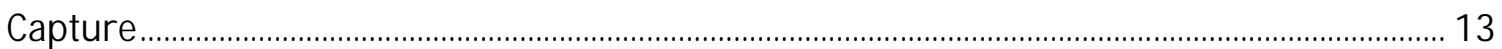

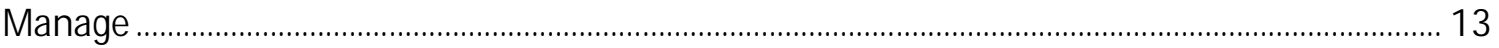

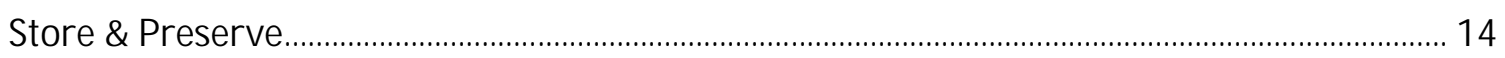

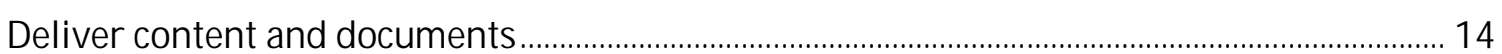

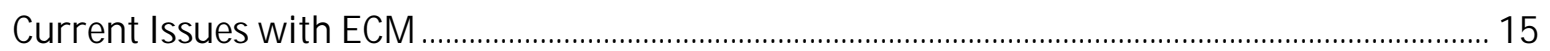

High Capital Expense \& associated maintenance costs............................................................................ 15

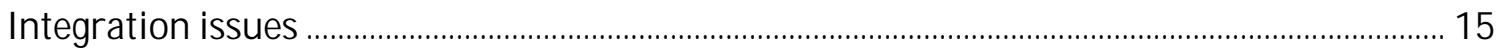

Prolonged Implementation Times .................................................................................................. 15

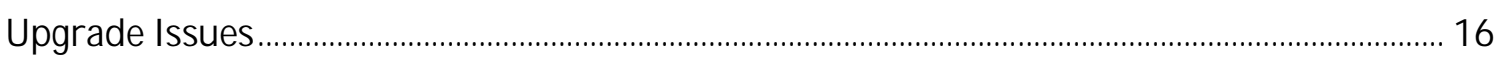

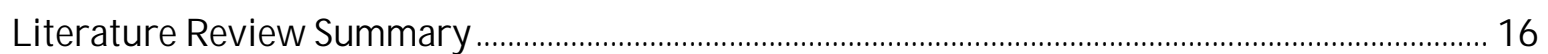

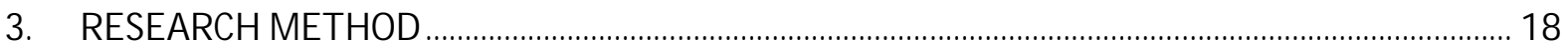

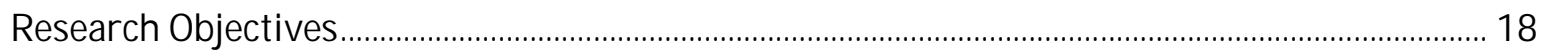

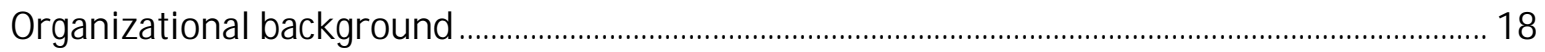

Research Design .............................................................................................................................. 19

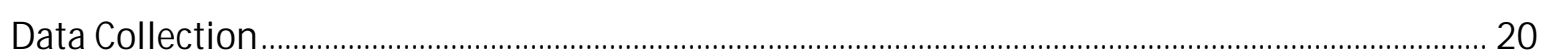




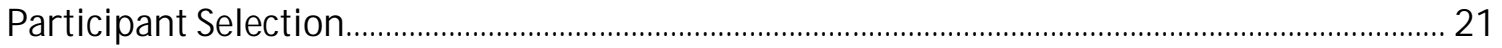

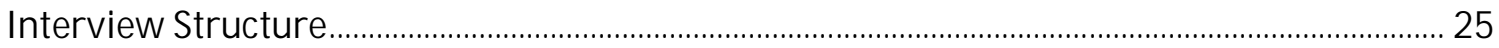

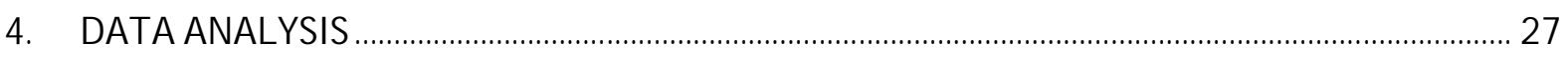

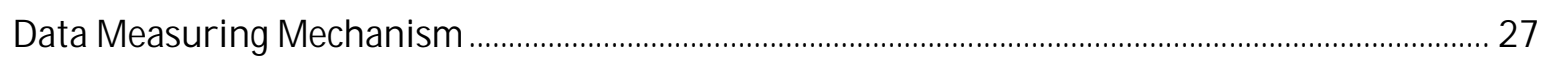

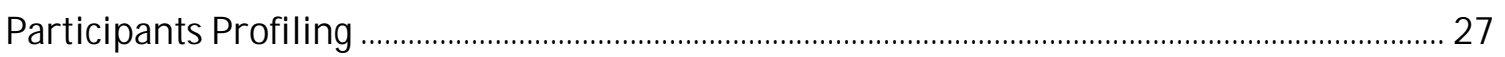

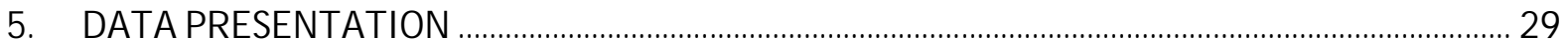

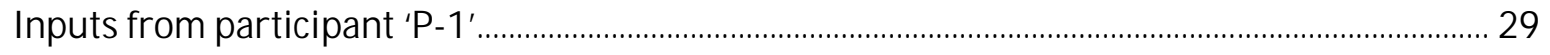

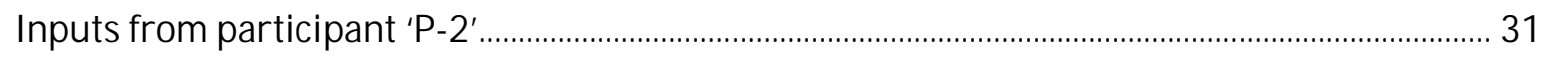

Inputs from participant ' $\mathrm{P}-\mathrm{3}^{\prime}$ '................................................................................................... 32

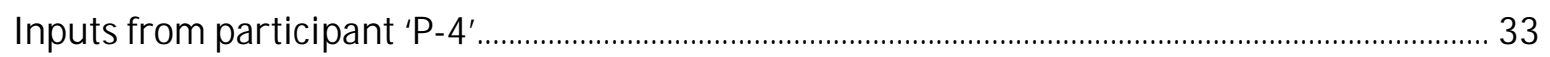

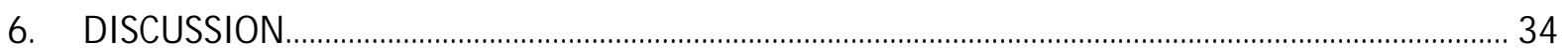

Migration costs too expensive to be justified ................................................................................................ 35

Inadequate infrastructure for remote branches leading to performance issues ............................... 35

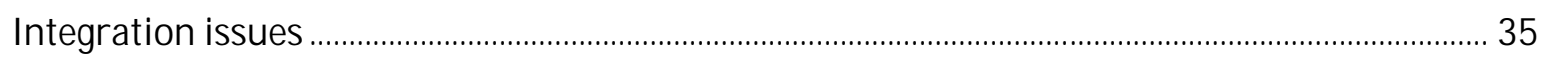

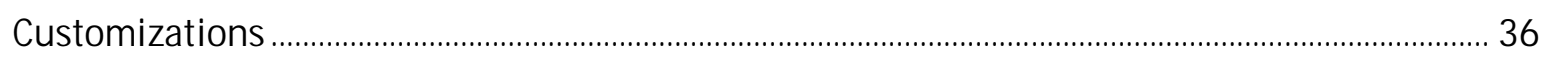

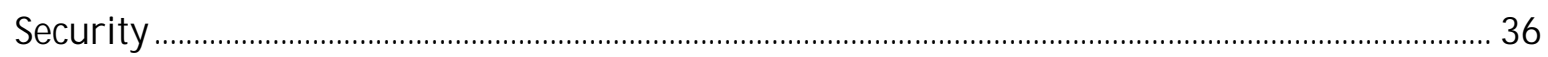

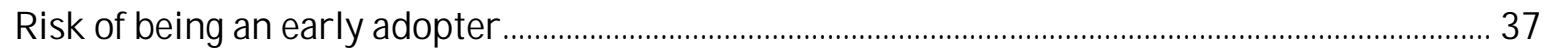

Potential lack of control over internal ICT processes................................................................................ 37

7. CONCLUSIONS ...................................................................................................................................... 38

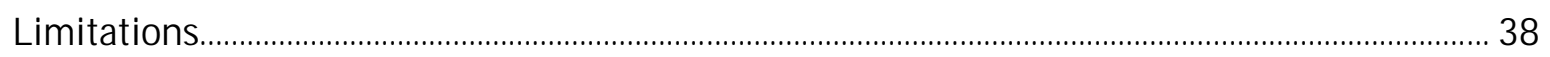

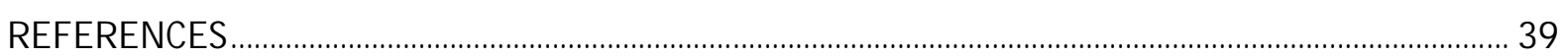

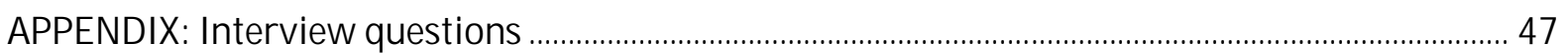

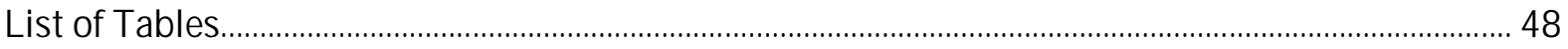

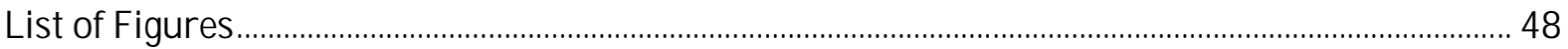




\section{INTRODUCTION}

In the early days of computing, there were "dumb terminals", which relied on a central computer for any processing needs (Herr, 1974). By the virtue of more affordable and powerful processors and ubiquitous connectivity, technology has spawned the development of cloud-based computing opportunities (Jenkins, 2010). Cloud based computing comprises a new way of utilizing and consuming IT services whereby the software-vendor runs and maintains all necessary hardware and software, while buyers access the software through the use of the Internet (Choudhary, 2007).

Cloud computing services generally provides services at three different levels. These levels are referred to as Infrastructure as a Service (IaaS), Platform as a Service (PaaS), and Software as a Service (SaaS) (Foster, Zhao, Raicu, \& Lu, 2008). SaaS is defined as a cloud based service where "a software vendor creates application software which runs on the infrastructure installed by an IaaS provider or on servers maintained by the application vendor which are connected to the Internet" (Rajaraman, 2014 p. 248). In the Global 100 Software Leaders report (Francis, 2014) conducted by PriceWaterhouseCoopers, it has been highlighted that revenues from the SaaS delivery model in the top 100 software leaders increased by $60 \%$. The expected revenue from this model is expected to reach $\$ 22.1$ billion in 2015 ("Gartner Says Worldwide Software-as-a-Service Revenue to Reach \$14.5 Billion in 2012," 2012). Both these reports highlight that SaaS adoption is continuing to reflect a healthy growth.

In the wake of popularity cloud based offerings have attained, New Zealand government, as part of its Government ICT (Information and communications technology) Strategy and Action Plan to 2017 ("Cloud Programme | ICT.govt.nz,"), has endorsed the use of a series of cloud services mainly to improve service delivery and eventuate substantial savings. Under the new plan, information is to be managed as an asset, which will be managed by its enabling technologies such as Enterprise Content Management as a Service (ECMSaaS).

While the benefits of cloud computing are widely discussed (Fonseca, 2008; Talukder \& Zimmerman, 2010; Waters, 2005), the issues that are associated with its adoption have gained relatively little attention (Morgan \& Conboy, 2013). In the wake of New Zealand government's ECMSaaS initiative ("Cloud Programme | ICT.govt.nz,") this case study 
takes a lead from the research dimensions identified by Alalwan and Weistroffer (2012) who identified a need for research on cloud computing in the context of ECM. The objective of this research is to investigate the challenges that are associated with the adoption of a SaaS based ECM solution through migrating from an on-premises ECM application. The word "on-premises" is being used in this research based on the definition "a type of software delivery model that is installed and operated from a customer's in-house server and computing infrastructure" by C. Janssen (2014).

A government sector organization that had made capital investment in setting up an onpremises ECM application was investigated. The organization had bought server hardware and acquired necessary software licences for the deployment of its onpremises ECM solution. The organization is currently evaluating their options for migrating from their existing on-premises ECM solution to a cloud based ECM solution, which has been referred to as ECMSaaS in this case study.

The key investigation explores the most relevant challenges, from an Information Technology (IT) standpoint, that effect an organization in migration of their onpremises ECM solution to a cloud based EDM solution. Qualitative research was chosen for this research and outputs from the semi-structured interviews are compared with literature in order to highlight the commonalities that exist with regards to the issues that are associated with the adoption of ECMSaaS. 


\section{LITERATURE REVIEW}

\section{THE BACKGROUND AND OVERVIEW OF SOFTWARE AS A SERVICE}

Historically, the idea behind cloud computing dates back to the 1960s when John McCarthy conceived an innovative idea that allowed users to share each other's data by linking to a central computer (McCarthy, 1962). This was considered as a significant contribution to the development of the Internet. He further predicted that computing facilities will be provided to the general public like a utility, which was the concept that later became a precursor of Cloud Computing (Zhang, Cheng, \& Boutaba, 2010). Information Technology kept evolving since and we have reached a point where the concept of sharing data, memory, and other resources has been realized in the form of Cloud Computing. Cloud computing is an umbrella service of which Software as a Service (SaaS) is a type (Desisto, Plummer, \& Smith, 2008; White, Brown, Deale, \& Hardin, 2009). Cloud computing is often equated to SaaS (White et al., 2009), therefore it will be referred to as SaaS hereafter in this case study.

Let us examine the history of Enterprise computing (Figure 1), which appears to have evolved through a series of incremental and gradual changes that can be aggregated to be termed as evolutionary waves. In the first wave, there were central mainframes, to which the data had to be carried manually in the form of a stack of punched cards - a technology that later became obsolete. The mainframes would then take these cards and process the data on them (Van den Ende \& Dolfsma, 2005). The customer had to spend millions in capital investment for those mainframes were in millions. Followed by that was the wave of client-server software architecture that introduced a layer of separation whereby one component (client) initiated the request, and the other component (server) responded with the requested information (Hashida \& Sakata, 2007). Despite the separation, both the components still needed to be directly connected for being able to communicate with each other. The next wave of enterprise computing was further enhanced the layer of (client-server) separation to an extent where client and server could remotely communicate with each other using the Internet Protocol (IP). Capital expenditure (CapEx) was still necessary for setting up the server side infrastructure, buying and implementing the software. 
Through all these waves of evolution, customers kept experiencing issues such as cost overruns, implementation delays, unforeseen maintenance and update costs, and misalignment with real-world business needs. In spite of all these issues, managers managed to justify the costs with the wider interest of providing competitive advantage to the organization. However, after the economic recession, there was a need to come up with a technology and business model that helped customers avoid these issues as it had increasingly become difficult justify such investments for reaping business advantages (Azarnik, Shayan, Alizadeh, \& Karamizadeh, 2013; Jensen, Schwenk, Gruschka, \& Iacono, 2009; Waters, 2005).

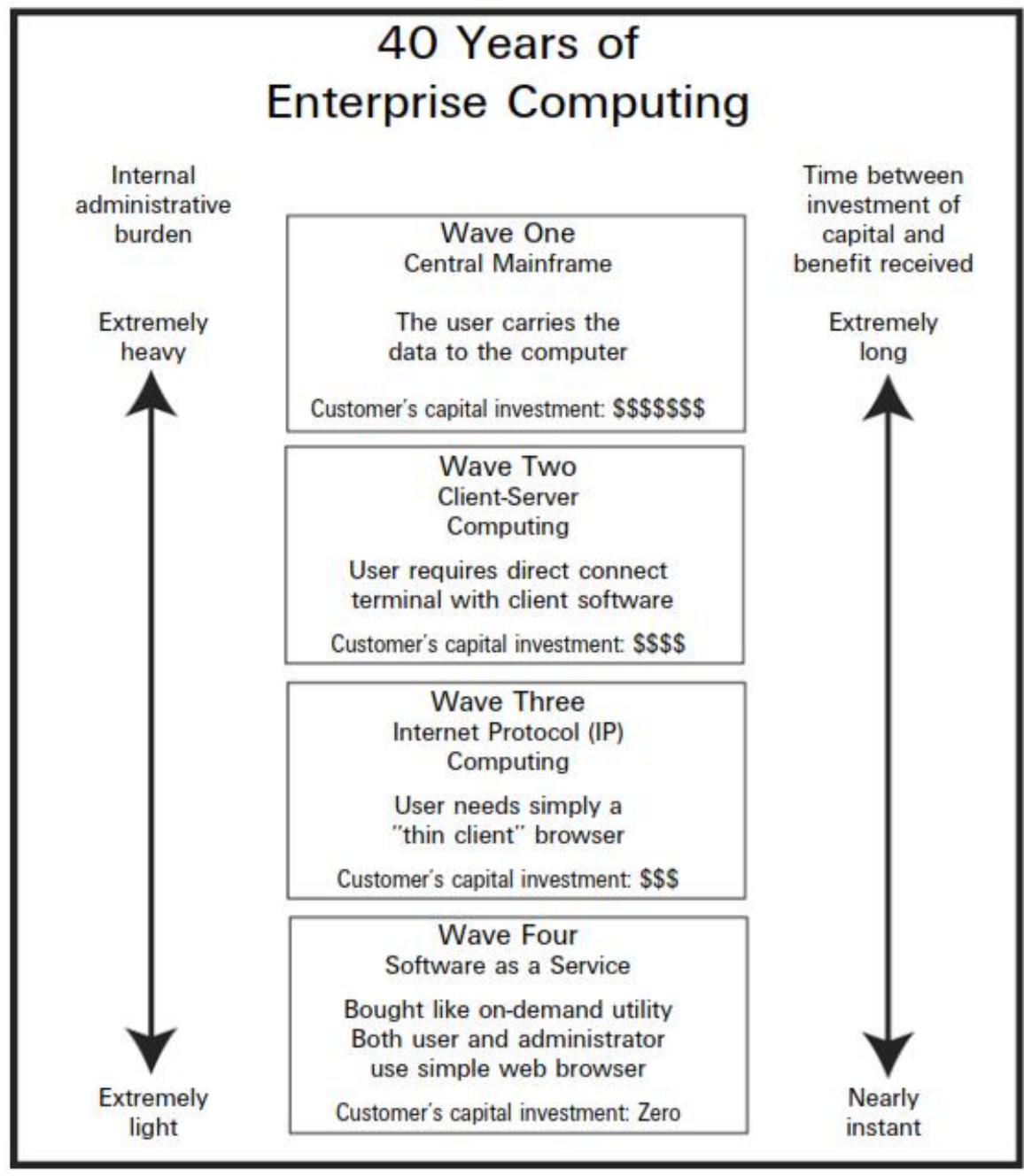

Figure 1: Evolution of enterprise computing, adapted from waters 2005.

With the advent of the fourth wave, service based model has been introduced using which the software could be brought as an on-demand utility. This model changed the way Information Technology systems were deployed as the ordinary as well as administrative users can consume the software from a simple web browser, which 
brings the initial CapEx to zero. Having a retrospective look at the last wave of enterprise computing will reveal that the computing power, which used to be centrally located in the case of mainframes as they handled data processing needs (Harrigan, 1988), has now been brought back to a central location on the network otherwise known as 'cloud' or the Internet. The idea that the infrastructure will be used twentyfour hours to justify high capital costs has been revisited. In addition to that, Cloud Computing enhanced that concept by servicing multiple customers individually at the same time. Vaquero, Rodero-Merino, Caceres, and Lindner (2008) observed the same by suggesting that cloud computing is considered as a shift in the geography of computation in a way that it has moved the computing infrastructure to the network in order to help reduce the costs with the management of hardware and software resources (Vaquero et al., 2008).

Another thing that kept happening through the evolutionary changes mentioned by Waters (2005) was that the enterprise software industry kept improving and maturing in ways that acted as enablers for realizing the Software as a Service utility model. These enablers have been discussed as follows:

\section{THE INTERNET}

The Internet was standardized to the point where each computer, regardless of the operating system it was running on, had to use the same communication protocol on the Internet. The user base kept expanding as well (Bailey \& Burd, 2006; Maher, 1998). According to a study conducted by Ottens (2006), Internet penetration had reached saturation point among large enterprises as well as small and medium enterprises in most countries around the world.

\section{MATURITY IN SOFTWARE}

The software industry had progressed as technologies such as client-server-based architecture (Berson, 1992), and web services (Levitt, 2001) were developed, which helped enabling the computers to communicate with each other regardless of their physical boundaries. 


\section{MATURITY IN COMMUNICATION}

With advancements in telecommunications such as Asymmetric digital subscriber line (ADSL), e.g., the Internet Service Providers (ISPs) were able to provide high speed Internet connections. Due to this, transfer of data between the two remotely connected computers was possible with such high speeds. Moreover, advancements in the IT industry such as rapid increases in communication bandwidth at competitive cost, means of communication have matured and acted as an enabler of cloud computing (Rajaraman, 2014).

\section{DEFINING CLOUD COMPUTING}

A commonly accepted definition was provided by National Institute of Standards and Technology (NIST) that defined cloud computing as "a model for enabling ubiquitous, convenient, on-demand network access to a shared pool of configurable computing resources (e.g., networks, servers, storage, applications, and services) that can be rapidly provisioned and released with minimal management effort or service provider interaction"(Mell \& Grance, 2011, p. 2).

There are four deployment models that associated with a cloud based service: public, private, community and hybrid clouds. The public cloud is based on the concept of sharing the services and infrastructure across multiple vendors and is provided by an off-site, third-party provider ( $\mathrm{Xu}, 2012)$. Private cloud, on the other hand, is leased to a single tenant to whom infrastructure and computational resources are provided. In case of a community cloud, infrastructure and computational resources are shared between a group of cloud consumers that have shared concerns. A hybrid cloud, as the name suggests, is a combination of two or more clouds that "remain as distinct entities but are bound together by standardized or proprietary technology that enables data and application portability" (Liu et al., 2011, p. 12).

In regards to the types of capabilities provided by the Cloud Computing, the services of cloud computing services can broadly be divided into three models: Infrastructure-as-aService (IaaS) (also known as Hardware-as-a-Service (HaaS) as suggested by Gong, Liu, Zhang, Chen, and Gong (2010)), Platform-as-a-Service (PaaS), and Software-as-a-Service (SaaS) (Gong et al., 2010; Vaquero et al., 2008; Zhang et al., 2010). This research will be 
focused on SaaS based cloud computing model which has been discussed in detail in the coming sections of this chapter.

\section{DEFINING SOFTWARE AS A SERVICE (SAAS)}

Although there have been many definitions for SaaS, none of them is considered to have been accepted as a standard one (Mäkilä, Järvi, Rönkkö, \& Nissilä, 2010). The definition by Rajaraman (2014) was chosen as relevant to this research. Rajaraman (2014, p. 248) defined SaaS as a type of a cloud based service where "a software vendor creates application software which runs on the infrastructure installed by an IaaS provider or on servers maintained by the application vendor which are connected to the Internet".

\section{SAAS BENEFITS}

Before SaaS, organizations had to bear the initial CapEx in setting up the infrastructure required for developing an application. In addition to that, the organizations had to then put up, later in the lifecycle of the application, with the expense involved in maintaining and upgrading the on-premises infrastructure as well as the application. Contrary to that, in case of SaaS, CapEx is converted into an incremental Operating Expense (OpEx) whereby the users are able to consume the application on "pay as you go" basis (Fox et al., 2009). It was further argued by Fox et al. (2009) that even with a scenario where 'pay as you go' model turn out to be more expensive, SaaS would still be worth adopting as it keep the investment protected from being over- or under-utilized. The solution is not only scalable, but can also be subjected to a reduced cost if the customer plans to borrow only a fraction of resources.

In case of SaaS based implementation, tasks such as installation, configuration, and deployment can be performed by the professionals from within their own data centres without having to bear the expenses that may be involved in bringing professionals to work on the client side. This helps increase the speed of deployment (Waters, 2005).

The nature of SaaS based software promotes scalability by allowing its customers to purchase additional capacities for resources such as data storage, bandwidth, and features, et cetera on an on-demand basis (Tsai, Huang, Bai, \& Gao, 2012).

One of the reasons behind low success rate of a traditional (non-SaaS) software projects is that they struggle to meet the delivery deadlines. They often end up consuming more budget than what is initially estimated. Moreover, the business requirements start 
getting misaligned by the time they are rolled out into production. By virtue of faster deployment SaaS helps address some of the underlying challenges.

With SaaS, the management of infrastructure as well as the application, which used to be a responsibility of the business, now rests with the cloud provider. This relocation of responsibility helps the business in getting indemnified against risks that are involved in the management of infrastructure and application (Waters, 2005).

\section{SAAS LIMITATIONS}

It has been highlighted in the recent reports (Francis, 2014; Hamerman, 2014) that the software industry continues to reflect a consistent and growing shift towards SaaS. However, SaaS, being a recently emerged technology, has not been without exceptions to the challenges that could prevent its adoption (Dillon, Wu, \& Chang, 2010). International Data Corporation (IDC), an American market research company, conducted a survey in 2009 highlighted challenges that prevent organizations from adopting Cloud Computing According to the survey, security, availability, and performance were the top three challenges that companies faced back then (Gens, 2009). Some of the key concerns that have been maintained in the literature are being discussed in the coming sections of this chapter.

\section{SECURITY}

On-premises applications are kept and managed on the servers that are residing within the enterprise boundary of an organization. This arrangement offers organizations to be flexible in tailoring their access control policies according to their needs (Popovic \& Hocenski, 2010).

On the other hand, in case of a SaaS, data as well as application is hosted outside the boundary of an organization at SaaS service provider's end. The data between the organization and the service provider flows over the network. This demands employment of strong network encryption techniques so that unauthorized access and leakage of sensitive information can be prevented (Popovic \& Hocenski, 2010).

Another sensitive issue regarding the data is related to its locality. According to the Information Security and Privacy guidelines set by the Information \& Communications Technology (ICT), no data above what has been classified as RESTRICTED should be 
held in a public cloud. Therefore organizations should pay carefully consider as to what kind of data goes into the cloud.

One of the benefits of New Zealand government's cloud initiative is that it "provides government agencies the confidence that their ICT infrastructure, including hosting, storage and backup, resides in a secure environment and is highly available." ("Infrastructure as a Service (IaaS) | ICT.govt.nz," 2014).

\section{INTEROPERABILITY}

The information an enterprise application is maintaining may also needed to be consumed by other applications, which may be residing on diverse systems. One way to achieve this would be to make each application have a copy of the same data. This approach means that the users unnecessarily will be spending additional time every time they go about maintaining copies of the same data in more than one application. However, if these applications are enabled to work together or inter-operate, exchange of information would become possible (Petcu, 2011). Similarly, a cloud based application also needs to exhibit interoperability so that the data across multiple applications remains synchronized. The concern however is that in order to be interoperable, the applications need to comply with a common set of standards. Even though many standardizing organizations are working to build cloud standards some of which are listed under ("Welcome to the Cloud Standards Wiki," 2012), concerns still exist over the standards that exist in the area of cloud computing (OrtizJr, 2011).

In terms of a unified set of ways in which the cloud consumers interact with the cloud providers, standard development organizations devised certain 'use cases'. Based on those, Lewis (2013) identified that for SaaS four basic cloud interoperability use cases namely User Authentication, Workload Migration, Data Migration, and Workload Management. These use cases are being explained as follows:

A typical scenario for the 'User Authentication' use case would be when a user needs to be authenticated before she or he could work on a given cloud based application. In order to be able to use the identity of a user to authenticate with another cloud provider, there needs to be a standard which both providers are qualified to comply with. Some of the common standards are Amazon Web Services Identity Access management (AWSIAM), OpenID, Web Services Security (WS-Security), et cetera. 
'Workload Migration' use case requires migration of a workload by extracting it from one type of cloud provider and uploading that to another. Similarly, we have 'Data migration', which correspond to the extraction of data from one cloud provider to another. This can be achieved if both old and new cloud providers support standard protocols including the likes of Simple Object Access Protocol (SOAP).

\section{VENDOR LOCK IN}

Unlike the Internet standards that were developed early on, which helped generating a wider adoption, standards for cloud computing have been going under a lot of discussion recently (Lewis, 2013; Rajaraman, 2014). In the absence of standards, enabling organizations to port their data from one cloud provider to another can be rather challenging. In the cloud community, this phenomenon is referred to as Interoperability, which potentially "locks" the data existing in a proprietary format with one of the SaaS providers (Brown \& Bielskus-Barone, 2013; Chow et al., 2009; Lewis, 2013). On that basis, for an organization to switch to another ECMSaaS provider may not be easier (Brown \& Bielskus-Barone, 2013; Chow et al., 2009; Lewis, 2013).

\section{REDUCED SUPPORT FOR INTEGRATION}

An organization may have applications with which their existing on-premises application interacts with for exchange of information. Let us assume that the customer would like to retain that integration with their new SaaS application. In order to achieve this, Application Programming Interfaces (APIs) exposed by the new SaaS based application will need to be utilized to develop integration between the applications. Given the absence of cloud computing standards, these APIs are proprietary and vary with the cloud provider therefore the realization of seamless data transfer between cloud-based and local application increases the complexity of integration (Lewis, 2013). The same applies when there is a need to transfer data between two SaaS based applications that are powered by different vendors. There too, the difference in APIs eventuates in making the integration much more challenging (Hai \& Sakoda, 2009). 


\section{DATA EXCHANGE}

SaaS applications typically access the software from a simple web browser (Waters, 2005) and are involved in consuming a large fraction of their time in transferring data on to the cloud for processing and storage of the data. Applications with such requirements are more data-intensive (Moore, Baru, Marciano, Rajasekar, \& Wan, 1999). Organizations shall be aware of Internet connectivity and bandwidth limitations to avoid data transfer bottle necks so that application's availability and performance is not an issue (Feng, Chen, \& Liu, 2010; Fox et al., 2009).

\section{LESS CUSTOMIZABLE}

In an on-premises setup, the application is typically customized to suit the needs of a given organization. SaaS applications, however, are usually shared across multiple customers while allowing them to configure the application to their needs. This way cloud providers can achieve 'multi-tenancy' for their SaaS based applications. For some organizations, however, these configurations may not offer enough flexibility for meeting specific requirements. In that case, true 'multi-tenancy' cannot be achieved as the application needs to operate as a separate instance so that it can be customized to meets specific requirements of a given organization (Bezemer \& Zaidman, 2010). This SaaS limitation was also highlighted by M. Janssen and Joha (2011), which relates to the concept of "High SaaS characteristics" and "Pure SaaS characteristics" mentioned by Mäkilä et al. (2010, p. 121). Firms that represent "High SaaS characteristics" are the ones that require "client specific deployment" (Mäkilä et al., 2010, p. 121).

Despite these issues, SaaS is continuing to reflect growth ("Gartner Says Worldwide Software-as-a-Service Revenue to Reach $\$ 14.5$ Billion in 2012," 2012) in favour of the benefits it has to offer. In the next section, an overview of the ECM has been provided along with the issues that the technology is faced with.

\section{THE BACKGROUND AND OVERVIEW OF ENTERPRISE CONTENT MANAGEMENT (ECM)}

The exponential growth of the Internet eventuated in a huge increase in the amount of information generated and shared by an organization (Blumberg \& Atre, 2003). More recently, the rapid increase in adoption of modern devices have provided new interfaces to facilitate the creation of content. In 2010 alone, over 1 petabyte of data was 
generated (Villars, Olofson, \& Eastwood, 2011). Experts suggested from 80 (Grimes, 2008) to 85 percent (Carnes \& Longtin, 2006; Shilakes \& Tylman, 1998) of all business information exist as emails, text documents, memos, images, videos, letters, chats, et cetera.

Enterprise Content Management was introduced to come to terms with sheer volume of content. It helps an organization in exploring full potential of the content. This content might be in the form of text files, which does not have a static, pre-defined structure like the data that is found in relational databases, which stores data in the form of rows and columns. Therefore a more accurate term for many of these data types might be 'semistructured' data (Hammer, McHugh, \& Garcia-Molina, 1997). For an organization to find, administer, and archive such volume of semi-structured data on an ongoing basis in a quick and reliable manner can be challenging. This is where value of an ECM product is realized and it makes an important topic for information systems (IS) research.

\section{DEFINING ENTERPRISE CONTENT MANAGEMENT}

Enterprise Content Management (ECM) as a term was first introduced and defined by Association for Information and Image Management (AIIM) as cited by Blair (2004), which has become an umbrella term for a set of technologies that help manage unstructured data (Simons \& vom Brocke, 2014). It can be defined as "the strategies, methods and tools used to capture, manage, store, preserve, and deliver content and documents related to organizational processes." ("AIIM - What is ECM? What is Enterprise Content Management?," 2014).

As reflected by the above definition, ECM is unique in that it is not just about the technology or a specific product itself. Part of it is people practicing the ECM solution in line with strategies and processes that are set by the organization (Paivarinta \& Munkvold, 2005).

\section{ECM ACTIVITIES}

Smith and McKeen (2003) asserted that for an organization to implement ECM, investment in addressing each of the four lifecycle stages of the content namely capture, organize, process, and maintain is required. As per AIIM's definition, below are some commonly categorised activities that are pertinent to practicing ECM in an organization: 


\section{CAPTURE}

'Capture' encompasses all activities that are associated with the collection of content (Smith \& McKeen, 2003). Even before being able to collect the data, an organization needs to define what type of content it needs to capture as cited by Smith and McKeen (2003) from Noorlander (2001) . An ECM system is likely to attract a wider acceptance within an organization if it captures the content by emulating the existing business processes. This often requires integration with local applications (Alalwan \& Weistroffer, 2012). Typically, the content would automatically be captured as a byproduct of collaborative work amongst ECM users thereby becoming part of an organization's invaluable knowledgebase (Jenkins \& Schaper, 2005). This content could be in structured or semi-structured form (Simons \& vom Brocke, 2014): paper documents, web pages, reports, spreadsheets, et cetera.

\section{MANAGE}

Capturing of content will not be helpful to any organization if it is not easily discovered when it is most needed. Therefore organizations need to concentrate their efforts in organizing their content.

Similar to the way information is organized in the form of rows and columns in a spreadsheet or a relational database, ECM software allows its users to organize semistructured data into a hierarchical structure, referred to as 'taxonomy' (Blumberg \& Atre, 2003; Smith \& McKeen, 2003). This taxonomy is often achieved by using 'metadata' (data about data) values that contains information such as author, version, as well as information about semantics of the content (Becker, Knackstedt, \& Serries, 2003). Business acumen can also be utilized to optimize categorization of the content. This helps in making the information easily retrievable (Smith \& McKeen, 2003).

Once content has been added, a typical ECM system provides features including but not limited to version management, and search and navigation (Kampffmeyer, 2004). Through version management, users can track changes that one or more users may have made to a given document. This way, multiple users can work in a collaborative manner without overwriting each other's contributions. 


\section{STORE \& PRESERVE}

One of the early challenges that organizations faced in managing their content was that important information ended up getting stored in users' private folders. This resulted in making the discovery really difficult (Nordheim \& Päivärinta, 2006). Rockley, Kostur, and Manning (2003) termed this phenomenon as 'Content Silo Trap'.

One of the primary tasks in setting up the ECM systems is to define taxonomy. ECM users are usually trained to add content to these folders with respect to the hierarchy dictated by the taxonomy (Munkvold, Päivärinta, \& Kristine, 2006). Moreover, these containers can be configured to abide by a set of security configurations, also known as security policies, so that once the content that is going to be added to them is governed by those security configurations. For example, all the documents that are contained in the 'shared' folder could be assigned to a 'Public content' security policy that will force the document to be viewable to every other ECM user in the organization. This is one of the approaches that the ECM software can offer an organization in order to make information discoverable and mitigate the risks of 'content silos'.

\section{DELIVER CONTENT AND DOCUMENTS}

Delivery of the content is the last stage of any ECM. Once the content has been added into an ECM system, in the form of emails, documents, recordings, et cetera, the administrative users of the system ensure that it remains accessible to the authorized users for as long as their organization is required to retain that for administrative, legal, fiscal, or research purposes (Blair, 2004; Huth, 2002). In New Zealand, Public Records Act 2005 governs as to when the information can be disposed of ("Legislation.govt.nz," 2014). In a nutshell, the content is subject to certain retention and disposal policies which again are configured and maintained in the ECM system (Blair, 2004). 


\section{HIGH CAPITAL EXPENSE \& ASSOCIATED MAINTENANCE COSTS}

As with any other on-premises based software, the organization has to spend money necessary in setting up an infrastructure that is necessary for the application to run on. A considerable amount of effort is then spent on buying software licences and hiring services in order to develop the application. Once the application goes live, the organization typically has to maintain a routine of maintenance to keep the application running for which budgets are allocated typically on annual basis (Paivarinta \& Munkvold, 2005).

\section{INTEGRATION ISSUES}

Given the widespread increase in the use of modern devices, content can now be accessed and managed through using heterogeneous repositories, each of which may have a proprietary technical format of its own. According to Jenkins and Schaper (2005, p. 9), "on average a single enterprise-wide deployment of ECM involves more than 20 unique solutions". Therefore, content from these sources is typically heterogeneous in nature (Munkvold et al., 2006) and is likely to attract additional effort for integrating and unifying information from a variety of sources. According to Bernstein and Haas (2008), this integration related work could consume about 40 percent of the project's budget. Moreover, this integration may not just be a one-time effort. Over a period of time, an organization could possibly introduce new products or upgrading their existing software stack. As a consequence, this could necessitate modifications to existing components and/ or development of new components so that the solution is able to use them for integration and unification of the content (Scott, Globe, \& Schiffner, 2004).

\section{PROLONGED IMPLEMENTATIONTIMES}

Of all the stages of a an ECM project lifecycle, most of the revenue is spent in implementation stage (Boiko, 2005). As mentioned earlier, in the interest of gain a wider acceptance within an organization, an ECM solution may need to be integrated with a variety of data repositories (Alalwan \& Weistroffer, 2012). Moreover it may also need to be personalized for emulating existing business processes. Such requirements add to the scope of the overall solution thereby prolonging the implementation phase of what initially was presumed to be a COTS implementation. 


\section{UPGRADE ISSUES}

In most cases, a standard "off the shelf" ECM offering is not sufficient to fulfil specific requirements of an organization (Nordheim \& Paivarinta, 2004). SaaS based offerings are no exception due to the limited configurability they have been able to offer (Jenkins, 2010) . Therefore the system may need to be enhanced to be able to interface with third party applications, simplification of user interfaces, et cetera (Soh, Kien Sia, Fong Boh, \& Tang, 2003). Code changes that are necessary to realize these customizations need to be carried forward whenever there is an upgrade. While organizations may take advantage of customizations in securing a greater user buy-in (Nah, Lau, \& Kuang, 2001), it can, on the other hand, add complexity possibly due to the custom code that was in conflict with the code that is present in the newer version thereby complicating the upgrade process. In the interest of coming to terms with some, if not all, of the above mentioned issues and benefiting from the advantages that SaaS based solutions claim to offer, ECM, in this research, is being viewed in a SaaS context. It investigates the challenges that are involved in the migration of an on-premises ECM application to an ECMSaaS application.

\section{LITERATURE REVIEW SUMMARY}

The value of central computing has been revisited in the form of cloud based computing through which multiple clients are serviced by the centrally located cloud provider. The cloud provider invests in setting up an infrastructure facility and attempts to bring the savings by maximizing the utilization of the infrastructure through servicing multiple clients at the same time. The client, on the other hand, no longer has to worry about managing the infrastructure as it is going to be done by the cloud provider. SaaS users are able to consume the application on "pay as you go" basis (Fox et al., 2009). Some of the key benefits that were identified during the literature review included but not limited to low cost of ownership, scalability, and faster deployment of the application.

While the revenues from cloud based offerings are expected to rise even higher in the coming years (Francis, 2014; "Gartner Says Worldwide Software-as-a-Service Revenue to Reach $\$ 14.5$ Billion in 2012," 2012), it does has certain limitations, which can be true of any emerging approach. Concerns including security, interoperability, vendor lock-in, reduced support for integration and data exchange, less customizability were found to have been associated with SaaS. 
Literature review then gives an overview of the ECM technology by highlighting its main activities that include capturing, management, storage, preservation, and delivery of the content to the organization. The ECM technology is faced with issues including high capital expense, maintenance costs, prolonged implementation times, issues related to its integration and upgrade.

This research extends on the New Zealand government's Cloud initiative ("Cloud Programme | ICT.govt.nz,") alongside the research dimensions that had been identified by Alalwan and Weistroffer (2012) after a comprehensive literature review of the ECM. It contributes to the ECM literature through investigating what are the challenges that are associated with the migration of an on-premises ECM application to an ECMSaaS application. The next section will explain the research method that has was adopted for this case study research. 


\section{RESEARCH METHOD}

This chapter explains the method of research, which shall be chosen carefully such that it enables the researcher to analyse the results in an appropriate manner (Gill \& Johnson, 2010).

The chapter starts by providing a brief overview of what the research objectives were. Followed by that is a brief overview of the organization that has been provided to introduce the context in which the research was conducted. Research design section will then explain the approach that was taken to execute the research. It also explains why qualitative research was chosen as the research strategy. Remaining sections of this chapter discuss how the data collection was approached followed by the details on how participants were selected and interviews were structured.

\section{RESEARCH OBJECTIVES}

The purpose of this investigation was to examine an organization, which had made capital investment in setting up an 'on-premises' ECM application, with the intent to explore the challenges associated with the migration to an ECMSaaS mainly from an IT viewpoint.

Findings from this research add to the SaaS literature specifically in the context of ECM applications. It was expected that this investigation will confirm some or all of the challenges that were identified during the literature review of ECMSaaS and possibly discover additional ones. Reflecting upon the identified challenges will help organizations in prioritizing their efforts in relation to migrating from their existing onpremises ECM applications to SaaS based alternates.

\section{ORGANIZATIONAL BACKGROUND}

This research was conducted in one of the government sector organizations, which is responsible for delivering a variety of services on behalf of New Zealand government. It employs more than 3000 employees and has over 90 different locations across New Zealand.

More than 6 years ago, the organization decided to buy a commercially off the shelf (COTS) ECM product that would meet their ECM requirements. For this, they invested in 
setting up the infrastructure, bought the necessary licenses of an ECM product, and engaged a local consulting company to gather their requirements for implementing an 'on-premises' ECM solution for them. During the course of implementation, the organization was made aware of the gaps between the current business practices and the functionality that the COTS (Commercial off the shelf) ECM could offer. Owing to the specific requirements of the organization, the consultancy company was required to modify the ECM application functionality. In addition to that, new software components were developed for facilitating the exchange of information with third party applications such as Novel GroupWise, et cetera. The system was tested successfully for approval by the business users and later put into production where one of the business units had started using it. The solution did undergo occasional version upgrades during the later stages of the maintenance; however these upgrades kept becoming more complex with the arrival of newer versions of the ECM product. The reason behind this complexity was that the major versions usually introduced architectural changes, as a result of which the customizations and integrations had to be modified accordingly, if not redeveloped from scratch. Adding to the worry is the fact that there is no high availability or disaster recovery solution in place and therefore the system is in a highly vulnerable state. Having a look retrospectively at the lifecycle of their existing ECM solution it can be realized that the maintenance phase of their on-premises solution is becoming burdensome in relation to the value that they are getting from it.

In the interest of benefiting from the advantages that a SaaS based solution claims to offer, the organization in the early stages of evaluating ECMSaaS options. This research will investigate the challenges that are involved in migrating to ECMSaaS from an ECM solution.

\section{RESEARCH DESIGN}

For the organization that was examined, cloud based offerings were an emerging field of interest. Only a couple of applications were known to have been adopted so far by the organization. The participants of the research were expected to provide insights based on their prior knowledge and experiences that were applicable in current context. This was the reason qualitative research was chosen as it could provide flexibility for examining the organization with maximum exploratory power (Boeije, 2009). 
Moreover, qualitative research method allows its researcher the ability to carry out an in-depth investigation (Feagin, Orum, \& Sjoberg, 1991) in a realistic context (Denzin \& Lincoln, 2005) and therefore was another reason why it was chosen for this research. Responses from the participants were compared to bring out the commonalities and differences (Knodel, 1997).

\section{DATA COLLECTION}

This section explains how the process of data collection was approached and how the ethical concerns that were relevant to this research were taken care of.

In order to be able to carry out this research, an application was formally logged with the Human Ethics Committee (HEC). A written approval was obtained from the HEC after which all the proposed participants of this research were personally approached and adequately informed about the intent of the investigation.

Based on the recommendation by DiCicco-Bloom and Crabtree (2006), the participation of the interviewees was formalized after having verbal consents on several occasions from the participants. The participants were kept aware of the progress verbally during the informal catch-ups in the earlier stages of the research at a high level without providing them any information that could possibly have influenced their opinions during the interviews. This approach helped in establishing rapport with the interviewees, which Douglas (1985) identified as an essential characteristic of the interviews.

In line with the chosen qualitative research approach, semi-structured interviews were selected as the data sources for this case study. The interviews were conducted on an individual basis. This way, feedback from the interviewees remained anonymous from each other, which according to DiCicco-Bloom and Crabtree (2006) helps protect the interest conflicts that may exist between the participants of the research.

At the beginning the interview, each participant was briefed about the context of the research as well as the objectives of the interview. During the interview, notes were taken from time to time for validating the response back with the interviewee. These notes were also helpful in asking any follow-up questions later on in the interview. 
The interviews took up to 60 minutes. These interviews were audio-recorded with prior consent of the participants and were later transcribed. The transcriptions were sent to their respective interviewees for verification and approval (Miles \& Huberman, 1994).

\section{PARTICIPANT SELECTION}

Despite the fact that the current solution was being used by a small unit within the organization, it was ensured that the relevant stakeholders were interviewed for their opinions on the case.

Four participants with the following designations were invited to participate in the research interviews. Three of them were the employees of the organization having designations as Solutions Architect (P-1), Service Delivery Manager (P-2), and Senior Information Advisor (P-3). Fourth participant was an on-site senior consultant (P-4) from a local consultancy firm who had been providing support for the organization's current ECM solution for the last five years. These participants have been summarized in the following Table 1: summary of the interviewees that describes their characteristics based on which they were chosen to be interviewed: 


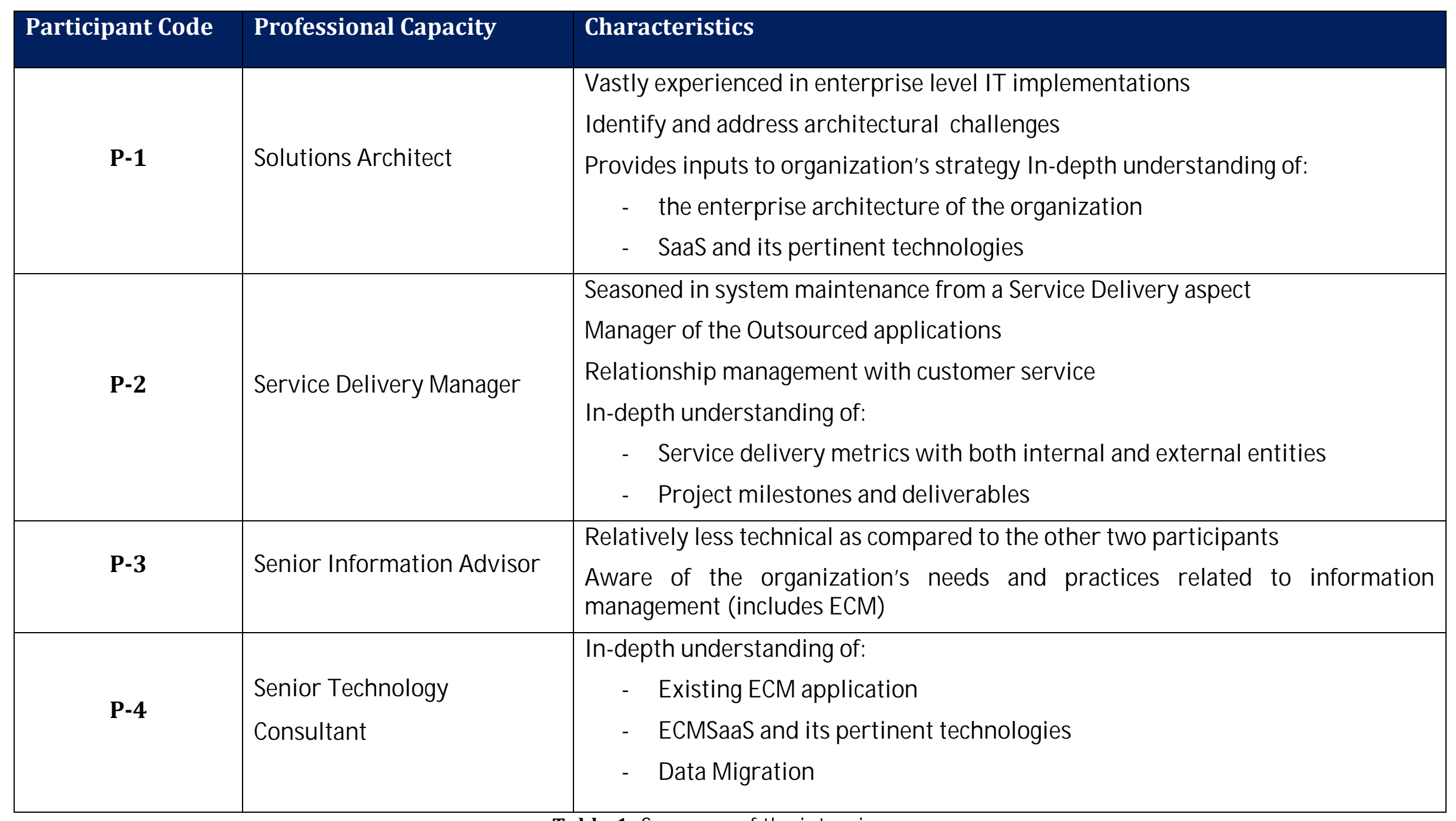

Table 1: Summary of the interviewees 
Participants P-1 (Solutions Architect), P2 (Service Delivery Manager), and P-4 (Senior Technology Consultant) were expected to be providing their opinions based on their:

1. Knowledge regarding the challenges associated with the migration of the current ECM solution

2. Past and on-going experiences with existing SaaS implementations

"Deficient requirements" is one of the major reasons behind most IT project failures (Hofmann \& Lehner, 2001, p. 58). P-3 (Senior Information Advisor), who is the business representative, becomes a key stakeholder for laying down the requirements that will drive the ECMSaaS implementation. On that basis, P-3 becomes a key stakeholder and hence needed to be interviewed.

\section{INTERVIEW STRUCTURE}

Due to the exploratory nature of the research, it was necessary to suppress "preemptive reduction of the data" that could have prevented discovery (Atieno, 2009, p. 16). On that basis, interview questions were ensured to be open-ended and descriptive in order to minimize this risk. A total of five questions were asked from all the recipients who responded to them in their respective capacities. The questionnaire has been attached in the Appendix: Interview questions.

The first question broadly captured the case under investigation and therefore the participants were expected to take most of the available time answering this question. Based on the guidelines by Turner (2010), the respondents were encouraged to reflect upon their past experiences that were applicable in the context of an ECMSaaS implementation while answering this question. It was intended that the respondents would bring out as many issues they possibly can think of without revealing any of the remaining questions to them.

The existing ECM solution had been heavily customized to meet specific needs of its users, in spite of realizing that it was making the maintenance lifecycle of the solution much more complicated and cost consuming. In case of SaaS applications, as mentioned during the literature review, configurations are provided to its users who can modify the behaviour of the application to a certain extent (Jenkins, 2010). The rationale behind the second question (Customization) was to get an idea of the affordable degree of customizations based on which the intensity of challenge could be identified. 
A cloud based service would be centrally accessible to the users who may potentially be accessing data from insecure devices. In the interest of keeping the access to the application secure, the IT department might well be interested in the enforcement of data security policies regarding access to ECMSaaS in order to remain compliant with the security standards (Popovic \& Hocenski, 2010). The organization therefore needed to be explored in the context of any challenges related to change management, which was the rationale behind asking Q-3.

Vendor lock in has been discussed many times in literature (Brown \& Bielskus-Barone, 2013; Chow et al., 2009; Lewis, 2013). It was therefore necessary to get a view of the organization on how it will deal with the challenges that are associated with the vendor lock-in.

Lastly, Q-5 was related to security, availability, and performance, which appeared as the top three challenges in a study by Gens (2009). It was important to obtain participants' views especially around the security concerns while attempting to establish whether government's cloud initiative had any impact on the relevance of these challenges.

The research methodology that has been explained in this section can be summarized into the following steps:

1. Extract responses from the semi-structured interviews based on the questions (as attached in Appendix: Interview questions).

2. Interpret the data from each interviewee with respect to his or her role and background.

3. Compare all responses qualitatively to conclude the challenges that the organization is likely to face. 
In accord with the research methodology explained in the previous chapter, the data analysis procedures are being defined in this chapter. These procedures will then be used to present the data analysis chapter.

\section{Data Measuring Mechanism}

As it can be observed from the participant selection section, the interviewees that were selected belonged to varying sections and levels in the organization. This approach was taken to help examine the (ECMSaaS migration challenges) phenomenon from diverse viewpoints thereby ensuring a wider and in-depth coverage of what challenges the organization is likely to be faced with.

\section{PARTICIPANTS PROFILING}

Given the varying nature of the interviewees, responses were likely to vary with respect to their areas of concern. On that basis, their responses were categorized in relevance to their key areas of concern. For example, response for Q-4 (see Interview Questions) relates to architectural standards and organizational policies. On that basis, response from P-1 would have been considered more relevant and therefore carries more weightage.

Given the relevancy of requirements to the success of an IT project (Hofmann \& Lehner, 2001), inputs from P-2 will play a key role in determining the level of complexity of a given challenge. This has earlier been discussed under Participant Selection section of this research.

Table 2 explains how the participants were categorized with respect to their roles and areas of concern in the context of the ECM application:

\section{\begin{tabular}{|l|l|}
\hline Participant Code & Key area of Input
\end{tabular}}

\begin{tabular}{|l|l|}
\hline $\mathbf{P}-1$ & Challenges that are related to infrastructure \\
\hline $\mathbf{P}-2$ & Challenges that are related to service delivery \\
\hline $\mathbf{P}-3$ & Challenges that are related to usability of the application \\
\hline $\mathbf{P - 4}$ & Challenges that are specific to the application functionality \\
\hline
\end{tabular}

Table 2: Approach to Data Collection 
Responses from the semi-structured interviews were transcribed. In line with recommendations by Walsham (1995), for a case study that is going to be interpreted as an outside observer, interviews were considered as the primary source. Same questions were asked from all participants of the semi-structured interviews. Responses obtained from all respondents were impartially examined in isolation from the researcher's past experiences, knowledge and learnings from the literature review. 


\section{DATA PRESENTATION}

This chapter focuses on the presentation of data that was collected from the interviews. The selection of participants and the mechanism through which data was to be collected has been explained in previous sections.

The interviews started by giving a brief introduction of the purpose of the research to the interviewee. Following that, the objective of the interview was communicated to set the scope and expectations with the interviewee. This approach was taken to help getting focused responses from the participants.

\section{INPUTS FROM PARTICIPANT 'P-1'}

P-1's initial concern regarding Q-1 was that implementation of an ECMSaaS was that "it is going to be hard to justify the cost involved in migrating to an ECMSaaS application when the ECM solution currently is used by less than $10 \%$ of the whole organization". He added that a "cloud based service does allow you to choose to only pay for the users that you migrate however that is not so much of an issue because the migration project will still cost you time and money [even for this small percentage of users] and unless you have actually got a wide user base to spread that costs across it's going to be very hard to justify".

Another concern regarding the content was commented as "The organization does not understand their data for most of its data probably excluding what we have in the current ECM solution."

P-1 identified three sources of data to which the ECM solution will need to be integrated in order to capture the data: i) Network drives, ii) Third party applications, and iii) Email service. He suggested that integrating their existing "third-party managed email service into the ECM solution can be a project in its own right" as effort will be spent in migrating existing e-mails.

He commented that there is a "high risk of being an early adopter" as "additional rigour and process will need to go into the management of the project".

Regarding security, P-1 mentioned that there is a concern regarding "where the data is hosted", "whether it is on-shore or off-shore", and "what laws apply". 
P-1 raised an issue related to performance by saying that the organization "has a very spread geography. At the moment the current ECM solution is used within the main office only which is using high speed networks but if the solution is made accessible to other branches of the organization, the latency can be up to a hundreds of milliseconds". As a consequence to that, "there could be network connection costs for making the service perform fast enough for all the users".

P-1 also mentioned that "as soon as anything goes out over the Internet, contractual management and performance goes out of the hand".

Regarding customizations, P-1 commented that "while this [a non-customized application] is cheaper and quicker approach", but at the same time "we found that the usability or the workflow doesn't always function as well for the organization". "Every time you put in an additional step, you are turning the user off effectively. They are going to hate the service", he added.

As for Q-3 that was related to change management, P-1 commented that in case of an ECMSaaS, "the teams can be geographically dispersed and they can still work together". He further added by saying "with my viewpoint, I can see the longer term benefits [of an enterprise wide ECMSaaS] but at the same time it's really hard to sell the users because they can't see the issues such as cost of the infrastructure side of keeping twenty years' worth of documents and never deleting anything". Further to that, P-1 mentioned that "The organization has a legal requirement to have presence in all major cities". P-1 foresaw a major challenge in that "you want to have ideal performance, but by centralizing the solution it can only be perfect performance for one group of users - the ones that are on reliable networks". Moreover, a web based centrally accessible system will be "available to users who may potentially be accessing a document from insecure devices which brings in a whole lot of security issues". P-1 confirmed that they were "not supporting BYOD (Bring your own device) at the moment, but there is definitely a government strategy moving towards that".

In reply to Q-4, P-1 indicated that "I think product/vendor lock-in is a reality whether it's provided as-a-service or in-house". He added, "The lock-in is generally based on the effort/cost to migrate data out of the current system and/or business processes (including user training) so it's normally easier to stick with the current product." 
P-1 replied to Q-5 by saying that "It's not really what's affordable; it's basically what we have to stick to. There are a number of documents related to security, protection of data, device encryption" and so on "that effectively we are mandated to comply with. So we don't have a choice."

\section{INPUTS FROM PARTICIPANT 'P-2'}

In reply to Q-1, P-2 remarked, “We purchased a few SaaS based applications that can be supported by one sole company. So it leaves us very weak power to negotiate. It's not only negotiate on the cost of the solution, but also negotiate on the performance. If you ask them to resolve a priority-1 issue within two hours, they will say we can only do in two days and we have got nowhere to go. Also, you need to consider data migration costs as well if you want to switch the provider".

P-2 also mentioned about the "risk of security" as the "data and/ or the service could be stored overseas and hence be prone to security risks".

In reply to Q-2, P-2 suggested, “From ICT's point of view, it’s always good to have a noncustomized one, but doesn't mean we have to go for it". P-2 further added, "What we can see here is, considering hundreds of applications that are being used currently in this organization, most of the incidents I have being seeing were with the customized bit and not with the core bit of the software application. For example, we have Office 365, which is cloud based, and there have hardly been any incidents. It's very stable."

Change management was one of the key areas of concern for P-2 in the capacity of a service delivery manager. He pointed out, "As a service delivery manager of the outsourced application team and also as a user of the application I believe every change should be recorded. The only way to record the change is to make the application provider go through the official change management process. For one of the SaaS applications that I am managing, we currently have a challenge for Change Management. The [SaaS] provider insists that the service is hosted externally, and the database is hosted externally as well hence they don't need to go through the official change management process. Their [SaaS provider's] view is that it doesn't affect our [organization's] entire system hence they don't need to go through the Change management, which is kind of arguable point but it isn't ideal from organization's point 
of view. That's why it is giving ICT a little bit harder time to have the providers to participate in the change management process."

P-2's response on Q-4 was similar to what he had mentioned for Q-1. P-2 foresaw commercial and serviceability issues especially when an application can solely be provided by a particular SaaS provider. P-2 reiterated that "you need to consider data migration costs as well if you want to switch the provider".

P-2 was "involved in signing contracts for a few SaaS applications". In reply to Q-5, P-2 indicated that "we require the service to be available at least 99.5 percent availability. Even though some businesses may argue that kind of increases the cost because they don't use the application after hours. But we still like to request for that". Regarding security, P-2 suggested that "I think it is one of the risks but not the top risk. As long as government's standards are met, I think that's fine".

INPUTS FROM PARTICIPANT 'P-3'

When responding to the first question, $\mathrm{P}-3$ remarked that "it is a new business model so there may be unknown factors around service delivery and performance". Moreover, "the solution does not yet have any reference sites or customers". P-2 was able to come up with other challenges when further questions were asked later during the interview.

P-3 clarified on the customizations aspect of the ECMSaaS regarding Q-2 by suggesting that "a COTS system would be unlikely to meet our business requirements around compliance". She referred to a number of customizations that they had as part of the current solution and suggested that "these customizations are critical to performing our jobs efficiently".

When replying to Q-3, P-3 commented that since ECMSaaS is a "different business model" and "has the potential to offer new capabilities such as mobile, et cetera, so there may be some policy development and socialisation required to implement it [a cloud based ECM] successfully."

In relation to the vendor lock-in phenomenon that was asked under Q-4, P-3 was not able to provide any concerns as the business case for the ECMSaaS was still in early stages. P-3 clarified that "we do not have enough information on vendor lock-in to have specific concerns". Similarly, regarding Q-5, P-3 highlighted that they were "still developing our business requirements so unknown at this stage”. 
P-4 who had been maintaining the current ECM application responded to Q-1 by suggesting that "ECM systems require extensive client-specific customizations. This organization is no different." He indicated that "the UI [User Interface] as well as core functionality of the product has been heavily customized". He further added that "unless the business is willing to let go some of them by re-engineering their business processes, considerable effort will be required to re-develop them in the new SaaS based ECM solution. So much so that the organization "might end up having a private instance of the [cloud based ECM] service". He expressed similar concerns over the "integration" by saying that the system "has been integrated with third-party applications. Those integrations will also need to be redeveloped in the new [ECMSaaS] system". He expressed that "the other thing that comes to my mind when we talk about cloud is security".

In reply to Q-2, P-4 commented that "a customized solution will always be the need for business as there will be a number of business processes that the organization has specifically designed suiting to their business practices". He added that "a cloud based ECM should be flexible enough to cater for customizations otherwise, it will be a big deterrent for serious ECM investment".

Regarding Q-3, P-4 suggested by saying that "I think end users and content owners in business will have anxiety about the performance and reliability of a cloud based system."

When responding to Q-4, P-4 remarked that "in my opinion, vendor lock-in is a concern that would occur even for on-premises ECM implementation, therefore, upfront screening and selection of service provider is critical".

In reply to the last question, P-4 commented regarding security, scalability, high availability standards by remarking that "this would depend upon business, compliance and regulatory requirements". He added that "as long as the business is happy in having their requirements met, ECMS should be acceptable". 


\section{DISCUSSION}

The results from semi-structured interviews that were conducted to explore the challenges that are acting as barriers to the adoption of a SaaS based ECM solution. In general, the results have resonated what had been identified during the literature review. Although for some of the issues, such as integration and customization, in particular, the propensity was found to be relatively higher as compared with the IDC's study (Gens, 2009).

Figure 2 entails a summarized list of challenges that were recognized during the interviews. These challenges have also been categorized across the various high level initiation, development, and operational/maintenance phases of a project.

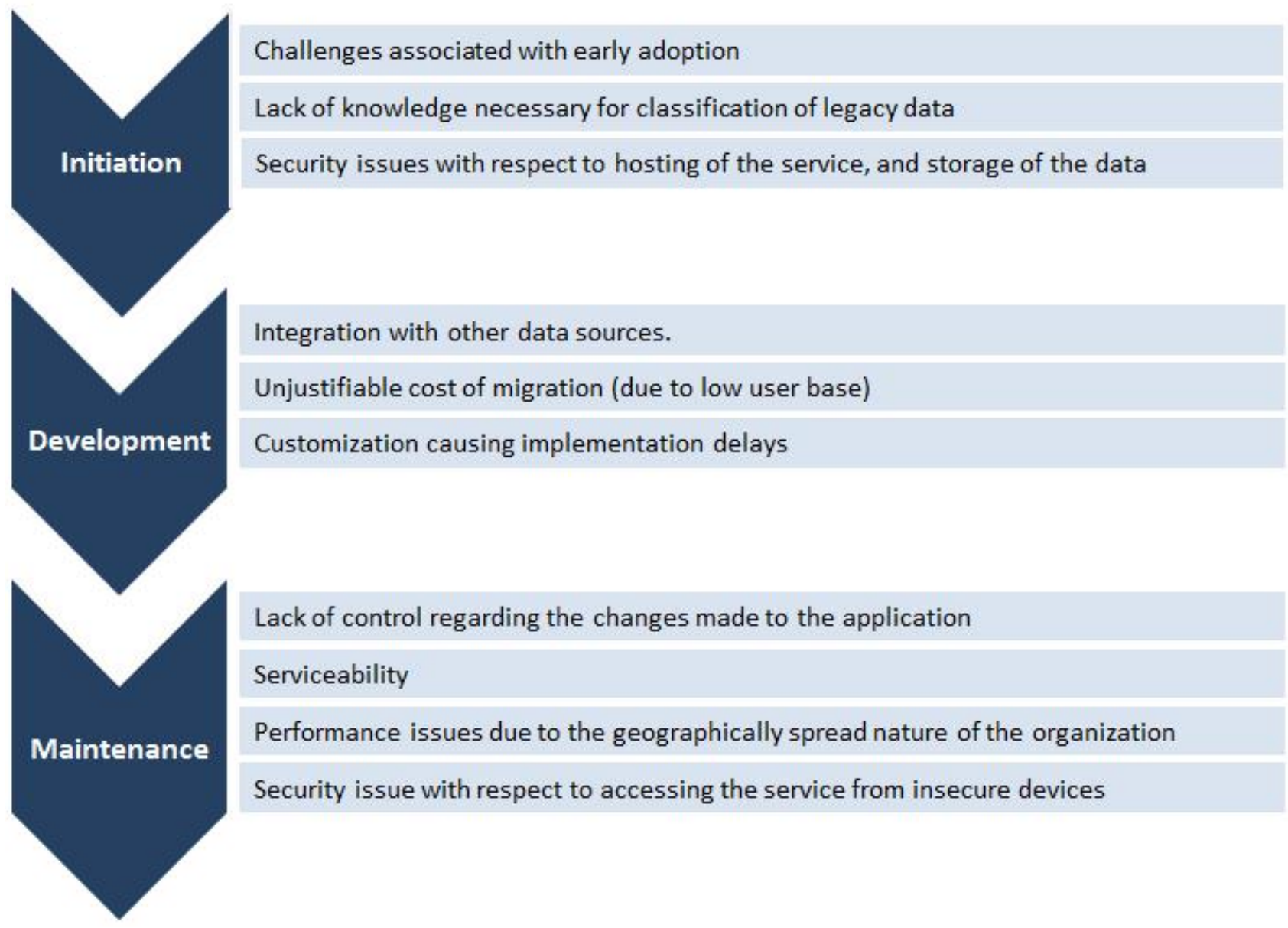

Figure 2: Categorized challenges

Above challenges are further discussed in the coming sections of this chapter. 


\section{MIGRATION COSTS TOO EXPENSIVE TO BE JUSTIFIED}

One of the key issues identified during the investigation was the migration of data from existing ECM as well as other repositories. The complexity of this task has also been asserted by Hai and Sakoda (2009). P-1 further suggested that at the moment the current ECM solution is used by only a small percentage of the organization and therefore the cost of migration, in spite of the fewer users, is going to be very hard to justify. The underlying challenge therefore is with the reduced utilization, say within a small percentage of users, of the ECMSaaS which in turn makes the cost of implementing an ECMSaaS solution rather unjustifiable.

\section{INADEQUATE INFRASTRUCTURE FOR REMOTE BRANCHES LEADING TO PERFORMANCE ISSUES}

The advancements in technology and communication played an instrumental role in realizing the SaaS utility model. However the organization was found to have spread geography, due to which some of the branches may be prone to latency issues due to unreliable network connections. This may likely not sit well with the expectations of the business (P-3) who had mentioned concerns about service delivery and performance. In addition to that, upgrading the infrastructure could be quite an expense as well. Therefore for organizations with dispersed locations, the SaaS will have clear performance implications unless significant amount is spent to upgrade the underlying infrastructure. This is where the role of New Zealand government's Ultra-Fast Broadband (UFB) could potentially come into play. However, New Zealand government's 'cloud first' program, on one hand, is promoting centralization of services and is aimed at achieving efficiencies, whereas on the other hand, the public sector organizations that are geographically spread are likely to face performance issues that may hinder them from performing their day to day jobs efficiently.

\section{INTEGRATION ISSUES}

As identified in the literature review, ECM system typically needs to be integrated with other applications for exchange of information. Given the disparate repositories that were identified in the organization, which in turn requires involvement from a variety of teams, integration could become quite challenging. Moreover, due to lack of interoperability standards, as well as fewer capabilities provided by cloud to cloud 
integration services as compared to on-premises ones, the organization's ECMSaaS initiative is likely to suffer from prolonged implementation timelines. This was highlighted as the hardest challenge for the organization by P-1 as a variety of applications need to communicate with each other with respect to different use cases (Lewis, 2013).

On one hand, the government is promoting centralization of services, whereas on the other hand, the organization had a range of applications (third party applications, email service to name a couple that were identified by P-1) that need to be integrated with the ECMSaaS solution. Moreover, since these applications were designed in isolation, and therefore enabling them for integration attracts additional costs in most cases as informed by P-1. Without having these integrations in place, the ECMSaaS would be unlikely to meet the business requirements around compliance as suggested by P-3.

\section{CUSTOMIZATIONS}

In addition to the integration requirements mentioned in the previous section, it was raised by all three participants that a COTS implementation of ECMSaaS is unlikely to meet the requirements that are specific to the organization. As quoted from Jenkins (2010) in the literature review, the ECMSaaS providers have not been able to provide enough depth in terms of configurability. Therefore the solution will need to be customized according to be able to meet the specific requirements. These customizations in turn inhibit the "pure SaaS characteristics" (Mäkilä et al., 2010, p. 121) and are likely to exhibit "High SaaS" characteristics instead. Therefore, a deployment that is specifically tailored to meet client requirements as mentioned by Mäkilä et al. (2010) would be more suitable to the organization with specialized requirements as highlighted by P-3.

\section{SECURITY}

All the respondents felt relatively confident about the issue of security, which had been ranked as a top concern IDC's report by in 2008 as well as 2009 (Gens, 2009). All participants seconded that as long as the standards set by the government are met, they should be fine. It is possible that Government's cloud first initiative has relieved the organization by providing them the "confidence that their infrastructure resides in a secure environment" ("Infrastructure as a Service (IaaS) | ICT.govt.nz," 2014) and 
therefore the mind-set has started to change as reflected by one of the respondents who remarked, "I think it is one of the risks but not the top risk".

\section{RISK OF BEING AN EARLY ADOPTER}

To start with, one of the risks foreseen by P-1 specifically was the risk of being an early adopter as this will potentially enforce additional rigour and oversight from the government.

\section{POTENTIAL LACK OF CONTROL OVER INTERNAL ICT PROCESSES}

One of the challenges identified by P-2 was related to a particular SaaS provider who was refusing by principle to participate in the change advisory board meetings of the Organization. This can potentially be avoided through a careful consideration and mutual agreement of the terms and conditions at the time when contract is being signed. The takeaway from this concern is that an organization that has any internal policies or processes to which the cloud provider needed to abide by, those shall be included in the contract so to avoid any misalignment of requirements. 


\section{CONCLUSIONS}

This case study highlighted the challenges that are associated with the adoption of ECM in SaaS based settings.

Despite the low cost, pay-as-you-go subscription benefits ECMSaaS has on offer, concerns including actual cost of migration (from an existing on-premises solution), limited support for integration with back-office and other SaaS applications (due to lack of interoperability standards), limited product configurability (that could eventuate into increased customizations demands), performance implications (potentially for geographically spread organization), along with concerns that are related to security and serviceability continue to pose challenges to the adoption of a cloud based ECM service.

On a positive note, however, initiatives such as New Zealand Government's 'cloud first' that are promising to provide, amongst other benefits, a secure environment to the government agencies. This in turn can potentially help raise their level of trust and promote cloud based services.

\section{LIMITATIONS}

While the organization was carefully analysed through qualitative method of research, it may well have provided a limited sample space based on which the conclusions could be generalized. Moreover, the opinions provided by the participants were based on their current knowledge of the existing ECM solution as well as past experiences of cloud based applications. An investigation of the organization in future, once it has migrated to the ECMSaaS, might reveal actual, rather than foreseen, challenges in retrospect. 


\section{REFERENCES}

What is enterprise content management? (2014). Retrieved August 3, 2014, from http:/ / www.aiim.org/ what-is-ecm-enterprise-content-management

Alalwan, J. A., \& Weistroffer, H. R. (2012). Enterprise content management research: A comprehensive review. Journal of Enterprise Information Management, 25(5), 441-461.

Atieno, O. (2009). An analysis of the strengths and limitations of qualitative and quantitative research paradigms. Problems of Education in the 21st Century, 13(1), 13-18.

Azarnik, A., Shayan, J., Alizadeh, M., \& Karamizadeh, S. (2012). Associated Risks of Cloud Computing for SMEs. Open International Journal Informatics, 1(1), 37-45. Retreived from http:/ / www.academia.edu/ download/ 30626279/ 58-229-1PB.pdf

Bailey, J., \& Burd, E. (2006, September). What is the current state of web accessibility? Paper presented at the Proceedings of the Eighth IEEE International Symposium on Web Site Evolution, Philadelphia, PA. doi: 10.1109/ WSE.2006.23

Becker, J., Knackstedt, R., \& Serries, T. (2003, June). Architectures for enterprise information portals: an approach to integrate data warehousing and content management. Paper presented at the European Conference on Information Systems, Naples, Italy. Retrieved from http:/ / is2.lse.ac.uk/ asp/ aspecis/ 20030139.pdf

Bernstein, P. A., \& Haas, L. M. (2008). Information integration in the enterprise. Communications of the ACM, 51(9), 72-79.

Berson, A. (1992). Client-server architecture. New York: McGraw-Hill.

Bezemer, C.-P., \&Zaidman, A. (2010). Multi-tenant SaaS applications: maintenance dream or nightmare? Paper presented at the Proceedings of the Joint ERCIM Workshop on Software Evolution (EVOL) and International Workshop on Principles of Software Evolution (IWPSE), Antwerp, Belgium. doi:10.1145/ 1862372.1862393

Blair, B. T. (2004). An enterprise content management primer. Information Management Journal, 38(5), 64-66. 
Blumberg, R., \& Atre, S. (2003). The problem with unstructured data. DM Review, 13, 4249.

Boeije, H. R. (2009). Analysis in qualitative research. London: SAGE Publications.

Boiko, B. (2005). Content management bible. Indianapolis: John Wiley \& Sons.

Brown, V., \& Bielskus-Barone, K. (2013, March). Software as a service (SaaS):

Revolutionizing software delivery through the cloud. In R. McBride \& M. Searson (Eds.), Proceedings of Society for Information Technology \& Teacher Education International Conference 2013 (pp. 3836-3840). Chesapeake, VA: AACE. Retrieved from http:// www.editlib.org/ p/ 48713.

Carnes, D., \& Longtin, N. (2006). US PATENT No. 200,602,481,29 A1. Minessota, MN: U.S. Patent and Trademark Office.

Choudhary, V. (2007, January). Software as a Service: Implications for Investment in Software Development. In Proceedings of the 40th Annual Hawaii International Conference on System Sciences (p. 209a). IEEE Computer Society.

Chow, R., Golle, P., Jakobsson, M., Shi, E., Staddon, J., Masuoka, R., \& Molina, J. (2009, November). Controlling data in the cloud: outsourcing computation without outsourcing control. In Proceedings of the 2009 ACM workshop on Cloud computing security (pp. 85-90). ACM.

Cloud Programme (2014). Retrieved July 2, 2014, from https:/ / ict.govt.nz/ programmesand-initiatives/ cloud-programme/

Denzin, N. K., \& Lincoln, Y. S. (2011). The SAGE handbook of qualitative research. California: SAGE publications.

Desisto RP, Plummer DC \& Smith DM 2008. Tutorial for understanding the relationship between cloud computing and SaaS. Stamford, CT: Gartner

DiCicco-Bloom, B., \& Crabtree, B. F. (2006). The qualitative research interview.Medical education, 40(4), 314-321.

Dillon, T., Wu, C., \& Chang, E. (2010, April). Cloud computing: issues and challenges. In Advanced Information Networking and Applications (AINA), 2010 24th IEEE International Conference on (pp. 27-33). IEEE.

Douglas, J. D. (1985). Creative interviewing. Beverly Hills, CA: SAGE Publications. Feagin, J. R., Orum, A. M., \& Sjoberg, G. (1991). A case for the case study. Carolina: UNC Press Books. 
Feng, J., Chen, Y., \& Liu, P. (2010). Bridging the missing link of cloud data storage security in AWS. Paper presented at the Proceedings of the 7th IEEE conference on Consumer communications and networking conference, Las Vegas, Nevada, USA. Retrieved from http:/ / dl.acm.org/ citation.cfm?id=1834304

Fonseca, B. (2008). SaaS benefits starting to outweigh risks. Computerworld,42(19), 12.

Foster, I., Zhao, Y., Raicu, I., \& Lu, S. (2008, November). Cloud computing and grid computing 360-degree compared. In Grid Computing Environments Workshop, 2008. GCE'08 (pp. 1-10). IEEE.

Fox, A., Griffith, R., Joseph, A., Katz, R., Konwinski, A., Lee, G., ... \& Stoica, I. (2009). Above the clouds: A Berkeley view of cloud computing. Dept. Electrical Eng. and Comput. Sciences, University of California, Berkeley, Rep. UCB/EECS, 28, 13.

Francis, Alayna (2014). Global Software Leaders Increase 'Software-as-a-Service' Revenues 60\% in One Year PwC Global 100 Software Leaders [Press release]. Retrieved from http:// press.pwc.com/global/global-software-leaders-increasesoftware-as-a-service-revenues-60-in-one-year/ s/ 6d1e7ae1-7d6d-428a-9129e2ec53e3b6d8

Gartner Says Worldwide Software-as-a-Service Revenue to Reach \$14.5 Billion in 2012. (2012). Retrieved from http:// www.gartner.com/newsroom/ id/ 1963815

Gens, F. (2009). New IDC IT Cloud Services Survey: Top Benefits and Challenges. IDC exchange.

Gill, J., \& Johnson, P. (2010). Research methods for managers. London: SAGE Publications.

Gong, C., Liu, J., Zhang, Q., Chen, H., \& Gong, Z. (2010). The characteristics of cloud computing. Paper presented at the the 39th International Conference on Parallel Processing Workshops. Washington, DC. doi: 10.1109/ ICPPW.2010.45

Grimes, S. (2008). Unstructured data and the 80 percent rule. Carabridge Bridgepoints. Hai, H., \& Sakoda, S. (2009). SaaS and integration best practices. Fujitsu Scientific and Technical Journal, 45(3), 257-264.

Hamerman, P. D., Holger Kisker, Ph.D., and David Murphy. (2014). Application Adoption Trends: The Rise Of SaaS: Forrester Research. Retrieved from https:/ / www.forrester.com/ Application+Adoption+Trends+The+Rise+Of+SaaS/ fulltext/ -/ E-RES116071

Hammer, J., McHugh, J., \& Garcia-Molin, H. (1997, September). Semistructured data: the TSIMMIS experience. In Proceedings of the First East-European conference on 
Advances in Databases and Information systems (pp. 22-22). British Computer Society. Swinton, UK.

Harrigan, K. R. (1988). Managing maturing businesses: restructuring declining industries and revitalizing troubled operations: Simon and Schuster.

Hashida, O., \& Sakata, H. (2007). Client/ Server Technology Handbook of Industrial Engineering (pp. 710-736): John Wiley \& Sons, Inc.

Herr, J. R. (1974). Microprocessor design for inteligent point-of-sale terminals. Computer, 7(7), 30-34.

Hofmann, H. F., \& Lehner, F. (2001). Requirements engineering as a success factor in software projects. IEEE software, 18(4), 58-66.

Huth, G. (2002). Retention and Disposition of Records: How Long to Keep Records and how to Destroy Them: University of the State of New York, State Education Department, State Archives and Records Administration, Government Records Services.

Infrastructure as a Service (IaaS) / ICT.govt.nz. (2014). Retrieved August 31, 2014, from https:/ / ict.govt.nz/ services/ show/ IaaS

What is On-Premises Software? (2014) Retrieved 6 July, 2014, from http:// www.techopedia.com/definition/26714/on-premises-software

Janssen, M., \& Joha, A. (2011). Challenges for adopting cloud-based Software as a Service (SaaS) in the public sector.

Jenkins, T. (2010). Managing content in the cloud. Ontario, Canada: Open Text Corporation.

Jenkins, T., Köhler, W. \& Schaper, H. (2005). ECM Technology: What You Need to Know (Vol. 2). Ontario, Canada: Open Text Corporation.

Jensen, M., Schwenk, J., Gruschka, N., \& Iacono, L. L. (2009). On technical security issues in cloud computing. Paper presented at the proceedings of the 2009 IEEE International Conference on Cloud Computing, Vancouver, BC. doi: 10.1109/ CLOUD.2009.60

Kampffmeyer, U. (2004). Trends in record, document and enterprise content management. Project Consult $\mathrm{CmbH}$.

Knodel, J. (1997). A case for nonanthropological qualitative methods for demographers. Population and development review, 847-853. 
Public Records Act 2005 No 40 (as at 30 June 2012), Public Act Contents. (2014). Retrieved August 20, 2014, from http:// www.legislation.govt.nz/ act/public/ 2005/ 0040/ latest/ DLM345529.html

Levitt, J. (2001). From EDI to XML and UDDI: A brief history of Web Services. Information Week.

Lewis, G. A. (2013). Role of standards in cloud-computing interoperability. Paper presented at the System Sciences (HICSS), 2013 46th Hawaii International Conference on.

Liu, F., Tong, J., Mao, J., Bohn, R., Messina, J., Badger, L., \& Leaf, D. (2011). NIST Cloud Computing Reference Architecture. NIST Special Publication, 500, 292.

Maher, M. (1998). An Analysis of Internet Standardization. Va. JL \& Tech., 3, 5-10.

Mäkilä, T., Järvi, A., Rönkkö, M., \& Nissilä, J. (2010). How to Define Software-as-a-Service - An Empirical Study of Finnish SaaS Providers. In P. Tyrväinen, S. Jansen \& M. Cusumano (Eds.), Software Business (Vol. 51, pp. 115-124): Springer Berlin Heidelberg.

McCarthy, J. (1962). Time-sharing computer systems (pp. 221-236): MIT Press, Cambridge, Mass.

Mell, P. M., \& Grance, T. (2011). SP 800-145. The NIST Definition of Cloud Computing: National Institute of Standards \& Technology.

Miles, M. B., \& Huberman, A. M. (1994). Qualitative data analysis: An expanded sourcebook. 1994. Beverly Hills: SAGE Publications.

Moore, R. W., Baru, C., Marciano, R., Rajasekar, A., \& Wan, M. (1999). Data-intensive computing. In F. Ian \& K. Carl (Eds.), The grid (pp. 105-129): Morgan Kaufmann Publishers Inc.

Morgan, L., \& Conboy, K. (2013). Factors affecting the adoption of cloud computing: An exploratory study. Paper presented at the proceedings of the 21st European Conference on Information Systems, Utrecht, Netherlands. Retrieved from http:/ / www.staff.science.uu.nl/ Vlaan107/ ecis/ files/ ECIS2013-0710-paper.pdf

Munkvold, B. E., Päivärinta, T., \& Kristine, A. (2006). Contemporary issues of enterprise content management. Scandinavian Journal of Information Systems, 18(2), 69100. 
Nah, F. F.-H., Lau, J. L.-S., \& Kuang, J. (2001). Critical factors for successful implementation of enterprise systems. Business process management journal, 7(3), 285-296.

Noorlander, W. (2001). Information management: who's controlling who? Online, 25(1), 36-38.

Nordheim, S., \& Paivarinta, T. (2004). Customization of enterprise content management systems: an exploratory case study. Paper presented at the System Sciences, 2004. Proceedings of the 37th Annual Hawaii International Conference on. doi: 10.1109/ HICSS.2004.1265255

Nordheim, S., \& Päivärinta, T. (2006). Implementing enterprise content management: from evolution through strategy to contradictions out-of-the-box. European Journal of Information Systems, 15(6), 648-662. doi: 10.1057/ palgrave.ejis.3000647

Ortiz Jr, S. (2011). The problem with cloud-computing standardization. Computer, 44(7), 13-16. doi: 10.1109/ MC.2011.220

Ottens, M. (2006). Use of the Internet among individuals and enterprises. Brussels: Eurostat.

Paivarinta, T., \& Munkvold, B. E. (2005). Enterprise content management: An integrated perspective on information management. Paper presented at the proceedings of the 38th Annual Hawaii International Conference on System Sciences, Washington, DC. doi: 10.1109/ HICSS.2005.244

Petcu, D. (2011). Portability and interoperability between clouds: challenges and case study. Paper presented at the Proceedings of the 4th European conference on Towards a service-based internet, Poznan, Poland. Retrieved from http:/ / link.springer.com/ chapter/ 10.1007/978-3-642-24755-2 6

Popovic, K., \& Hocenski, Z. (2010). Cloud computing security issues and challenges. Paper presented at the MIPRO, 2010 proceedings of the 33rd international convention.

Rajaraman, V. (2014). Cloud computing. Resonance, 19(3), 242-258. doi: 10.1007/ s12045-014-0030-1

Rockley, A., Kostur, P., \& Manning, S. (2003). Managing enterprise content: A unified content strategy. Boston: New Riders.

Scott, J., Globe, A., \& Schiffner, K. (2004). Jungles and gardens: the evolution of knowledge management at JD Edwards. MIS Quarterly Executive, 3(1), 37-52. 
Shilakes, C., \& Tylman, J. (1998). Enterprise Information Portals. Enterprise Software Team. Retrieved from http:/ / ikt.hia.no/ perep/ eip_ind.pdf

Simons, A., \& vom Brocke, J. (2014). Enterprise content management in information systems research. Berlin Heidelberg: Springer. doi: 10.1007/978-3-642-397158_1.

Smith, H. A., \& McKeen, J. D. (2003). Developments in practice VIII: Enterprise content management. The Communications of the Association for Information Systems, 11(1), 41.

Soh, C., Kien Sia, S., Fong Boh, W., \& Tang, M. (2003). Misalignments in ERP implementation: a dialectic perspective. International Journal of HumanComputer Interaction, 16(1), 81-100.

Talukder, A. K., \& Zimmerman, L. (2010). Cloud economics: Principles, costs, and benefits (pp. 343-360). London: Springer.

Tsai, W. T., Huang, Y., Bai, X., \& Gao, J. (2012, April). Scalable architectures for SaaS. Paper presented at the 15th IEEE International Symposium on object/ component/ service-oriented real-time distributed computing workshops, Shenzhen, Guangdong. doi: 10.1109/ ISORCW.2012.44.

Turner, D. W. (2010). Qualitative interview design: A practical guide for novice investigators. The Qualitative Report, 15(3), 754-760.

Van den Ende, J., \& Dolfsma, W. (2005). Technology-push, demand-pull and the shaping of technological paradigms-Patterns in the development of computing technology. Journal of Evolutionary Economics, 15(1), 83-99.

Vaquero, L. M., Rodero-Merino, L., Caceres, J., \& Lindner, M. (2008). A break in the clouds: towards a cloud definition. ACM SIGCOMM Computer Communication Review, 39(1), 50-55.

Villars, R. L., Olofson, C. W., \& Eastwood, M. (2011). Big data: What it is and why you should care. White Paper, IDC.

Walsham, G. (1995). Interpretive case studies in IS research: nature and method. European Journal of Information Systems, 4(2), 74-81.

Waters, B. (2005). Software as a service: A look at the customer benefits. Journal of Digital Asset Management, 1(1), 32-39.

Welcome to the Cloud Standards Wiki. (2012). Retrieved September 2, 2014, from http:// cloud-standards.org/ 
White, B. J., Brown, J. A. E., Deale, C. S., \& Hardin, A. T. (2009). Collaboration using cloud computing and traditional systems. Issues in Information Systems, 10(2), 27-32.

$\mathrm{Xu}, \mathrm{X}$. (2012). From cloud computing to cloud manufacturing. Robotics and ComputerIntegrated Manufacturing, 28(1), 75-86. doi: http:// dx.doi.org/ 10.1016/j.rcim.2011.07.002

Zhang, Q., Cheng, L., \& Boutaba, R. (2010). Cloud computing: state-of-the-art and research challenges. Journal of internet services and applications, 1(1), 7-18. 


\begin{tabular}{|l|l|}
\hline No. & Question \\
\hline Q-1 & $\begin{array}{l}\text { Describe your concerns about the transition to a new SaaS based } \\
\text { ECMS? }\end{array}$ \\
\hline Q-2 & $\begin{array}{l}\text { Explain your preferences for a customized ECMS compared to a } \\
\text { standardized SaaS ECM Service? }\end{array}$ \\
\hline Q-3 & $\begin{array}{l}\text { Describe any change management problems you can anticipate by } \\
\text { implementing a SaaS based ECMS? }\end{array}$ \\
\hline Q-4 & $\begin{array}{l}\text { Describe your concerns about vendor lock-in for a SAAS based } \\
\text { ECMS implementation? }\end{array}$ \\
\hline Q-5 & $\begin{array}{l}\text { Explain the standards / criteria applicable to the Security, } \\
\text { Scalability, and High Availability of the cloud based ECMS. What } \\
\text { level is affordable in your opinion? }\end{array}$ \\
\hline
\end{tabular}




\section{LIST OF TABLES}

Table 1: Summary of the interviewees. 24

Table 2: Approach to Data Collection 27

\section{LIST OF FIGURES}

Figure 1: Evolution of enterprise computing, adapted from waters 2005. 4

Figure 2: Categorized challenges 34 